\title{
Assessment of Enteric Helminthes Ova on Ready to Eat Selected Vegetables (Garden Egg, Cucumber and Carrot) in Ushongo LGA of Benue State
}

\author{
Yandev D. ${ }^{1,3}$, Abam M. J. ${ }^{3}$, Olasan J.O. ${ }^{2}$, \\ Ishwua M. N. ${ }^{3}$, Osar J. S. ${ }^{3}$
}

\begin{abstract}
${ }^{1}$ Department of Microbiology, Water and Public Health Research Group, University Of Nigeria Nsukka ${ }^{2}$ Department of Botany (Biotech and Environmental Sc.Unit), Federal University of Agriculture, Makurdi, Nigeria ${ }^{3}$ Department of Microbiology, University of Mkar, Gboko, Benue State, Nigeria
\end{abstract}

\begin{abstract}
The aim of this work was to investigate the level of enteric helminthes ova contamination on ready to eat selected vegetables in Ushongo Government of Benue state. The sampling locations comprised of three major markets: Ikyobo, Lobi and Lessel markets. A total of 270 samples were collected, 90 samples in each market (30 carrots, 30 garden egg and 30 cucumber). The samples were transported aseptically to the laboratory for egg analysis using centrifugation, microscopy and standard identification guide. Carrot was the most contaminated vegetable with a total of 63 contaminated samples out of 90 samples, hence percentage contamination was $70 \%$. Cucumber and garden egg had percentage contamination of $57 \%$ and $55 \%$ respectively. From a total of 270 vegetable samples investigated, 175 were contaminated with helminthes egg, thus resulting in $64.8 \%$ vegetable contamination in Ushongo LGA. Based on market type and location, contamination was highest in Lessel market (72.2\%) followed by Lobi market $(63.3 \%)$ and Ikyobo market $(58.8 \%)$. Vegetable contamination in the three location was statistically the same $\left(\chi^{2}=1.76, \mathrm{P}>0.05\right)$ as there was no significant association between market locations and the number of contaminated vegetables. In cucumber, Entamoeba histolytica was the highest contaminant (39\%) followed by Entamoeba histolytica (17\%), and Giadia lamblia (12\%). In carrot samples, Entamoeba coli (21\%) and Entamoeba histolytica (21\%) were the most occurring eggs isolated. This was followed by Chilomastix mesnili (16\%) and Iodamoeba buestchili (10\%). Others are: Trichuris trichiura (8\%), Ascaris lumbricoides (6\%), Entamoeba nana (6\%) and Ancyclostoma duodenale (5\%). In garden egg, Giardia lamblia was the most common contaminant (33\%). Also found were species of the genera Entamoeba and other species found in cucumber. A total of 14 egg types of different species were identified. Entamoeba histolytica (20\%), Entamoeba coli (19\%), Giardia lamblia (17\%) and Chilomastix mesnili $(10 \%)$ were the top four egg contaminants. Others species occurred in $<10 \%$. The high prevalence of enteric helminthes ova across the various markets was a reflection that vendors, producers and consumers are prone to parasitic attacks as a result of eating raw or uncooked vegetables in the study area. The information given in this report is crucial in the prevention of disease outbreaks associated with enteric helminthes in the study area.
\end{abstract}

Keyword: Contamination, Enteric helminthes, Ushongo LGA, Vegetables

\begin{abstract}
Introduction
Vegetables are important component of a healthy diet rich in a number of essential vitamins including Vitamin C, Vitamin B12, Niacin and Riboflavin and mineral element such as iron (Syngletary et al., 2005). Despite the health benefits, vegetables have been known to serve as vehicle to human disease causing agents. The channels through which vegetables get to the final consumers are possible routes of contamination and any unhygienic practices in their preparation could lead to incidence of human illness or infection resulting from the consumption of
\end{abstract}

contaminated products. Consumption of raw or unhygienically prepared vegetables is considered a risk factor for human parasitic infection (FAO, 2010). Helminthes are worm-like organisms living in and feeding on living hosts. They receive nourishment and protection while disrupting their hosts' nutrient absorption. This can cause weakness and disease of the host. Those helminthes that live inside the digestive tract, of humans and other animals are called intestinal parasites. In their adult forms, helminthes cannot multiply in humans (CDC, 2014). Helminthes are able to survive in their mammalian hosts for many

This article is published under the terms of the Creative Commons Attribution License 4.0 Author(s) retain the copyright of this article. Publication rights with Alkhaer Publications. Published at: http://www.ijsciences.com/pub/issue/2019-07/

DOI: 10.18483/ijSci.2104; Online ISSN: 2305-3925; Print ISSN: 2410-4477 
years due to their ability to manipulate the immune response by secreting immunomodulatory products (Jirillo et al., 2014).

All helminthes produce eggs (also called ova) for reproduction. These eggs have a strong shell that protects them against a range of environmental conditions. The eggs can therefore survive in the environment, outside their hosts for many months or years. Many but not all of the worms referred to as helminthes belong to the group of intestinal parasites. An infection by a helminth is known as helminthiasis, helminthes infection or intestinal worm infection. (CDC, 2014). Vegetables can become contaminated with enteric helminthes throughout the process of planting to consumption, the extent of contamination depends on some factors such as use of treated wastewater and water supplies contaminated with sewage as an organic agricultural fertilizers and for irrigation coupled with the unhygienic practices of the farmers during harvest, post harvest handling by vendors, poverty and hygienic conditions of preparation (Amoah et al., 2007). The consumption of vegetable and outbreak is increasing daily as consumers strive to eat healthy diet and benefit from the year round availability of these products that up till recently were considered to be seasonal, global trade in vegetables and change in horticultural practices have enable this year round abundance to be possible, However, recent epidemiological reports have shown a high risk associated with vegetable consumption due to parasitic contamination if not properly handled. Ushongo Local Governmemt Area of Benue State in Nigeria is popular in the production and marketing of vegetable crops in high volumes. The three major markets are major locations where many vegetables are sold and distributed to many parts of the State. The aim of this work was to investigate the level of enteric helminthes ova contamination on ready to eat selected vegetables in Ushongo Government of Benue state.

\section{Materials and Methods \\ Study Area}

This study was carried out in Ushongo LGA of Benue State, Nigeria. The headquarter is Lessel,

It is bounded at the North by Gboko Local Government Area and Buruku Local Governments Area, South at by Vandeikya Local Government Area, East at the Kwande Local Government Area, and West by Konshisha Local Government Area. Agriculture is the mainstay of the people's economy. With predominantly local tools, agricultural products are produced in varying degrees across the local government area. In more cases, such products serve a dual purpose as both cash and food crops. Indeed, just as Benue State is regarded as the food basket of the nation, Ushongo may well pass as the food basket of Benue State. Citrus fruits and mangoes are the principal products of Ushongo people. Indeed, Ushongo local government is the singular largest producer of citrus fruits in the whole of Benue State.

\section{Study locations and sample collection}

The sampling sites comprised of three major markets in Ushongo Local government which include: Ikyobo market, Lobi market and Lessel market. A total of 270 samples were collected, 90 samples in each market (30 carrots, 30 garden egg and 30 cucumber). The samples were transported aseptically to the laboratory for analysis.

\section{Sample analysis}

Samples were washed with physiological normal saline $(0.85 \% \mathrm{NaCl})$. The suspensions were strained through a clean sieve to remove undesirable materials. The top layer was discarded and the remaining was centrifuged at 2000rpm for 15 minutes as described by Adamu et al. (2012). The supernatant was discarded and the sediment was carefully mixed and a drop placed on grease free slide with the addition of a tiny drop of iodine. A clean cover slip was gently placed to avoid air bubbles and over flooding.

\section{Isolation and identification of parasites}

The method used for the identification and isolation of enteric helminthes ova was microscopic examination. The Enteric helminthes ova were examined under the microscope using x10 and x40 objective lenses. The ova were identified as described by Cheesbrough (2004) and Castro and Baron, 1996).

\section{Results and Discussion}

Table 1 presents the occurrence of contamination of vegetables in the three markets.in total, carrot was the most contaminated vegetable with a total of 63 contaminated samples out of 90 samples, hence percentage contamination was $70 \%$ as shown in Figure 1. Cucumber and garden egg had percentage contamination of $57 \%$ and $55 \%$ respectively. From a total of 270 vegetable samples investigated, 175 were contaminated with helminthes egg, thus resulting in $64.8 \%$ vegetable contamination in Ushongo LGA. Similar findings was reported in Jos markets and in Maiduguri where fresh vegetables were found to be highly contaminated with parasitic eggs (Adamu et al., 2012; Idahosa, 2011). Based on market type and location, contamination was highest in Lessel market (72.2\%) followed by Lobi market (63.3\%) and Ikyobo market $(58.8 \%)$ as shown in Figure 2. In Lessel market, garden egg was the most contaminated vegetable (24 out of 30 samples). In Lobi market, it was carrot (26 out of 30 samples) and in Kyobo market it was cucumber (20 out of 30 samples). Vegetable contamination in the three location was statistically the same $\left(\chi^{2}=1.76, \mathrm{P}>0.05\right)$ as there was no significant association between market locations and the number of contaminated vegetables. The three markets had equal chances of fruit contamination depending on the level of hygiene by the farmers, handlers and the source of contaminants. 
Assessment of Enteric Helminthes Ova on Ready to Eat Selected Vegetables (Garden Egg, Cucumber and Carrot) in Ushongo LGA of Benue State

Table 1: The frequency of vegetable contamination in different markets within the study area

\begin{tabular}{lllll}
\hline & Vegetables & & & \\
\hline Markets & Cucumber & Carrot & Garden egg & Total \\
Lessel & 22 & 19 & 24 & $65(72.2 \%)$ \\
Lobi & 15 & 26 & 16 & $57(63.3 \%)$ \\
Ikyobo & 20 & 18 & 15 & $53(58.8 \%)$ \\
Total & $57(63.3 \%)$ & 63 & 55 & 175 \\
& & $(70 \%)$ & $(61.1 \%)$ & $(64.8 \%)$ \\
\hline
\end{tabular}

$\chi^{2}=1.76, \mathrm{P}>0.05$

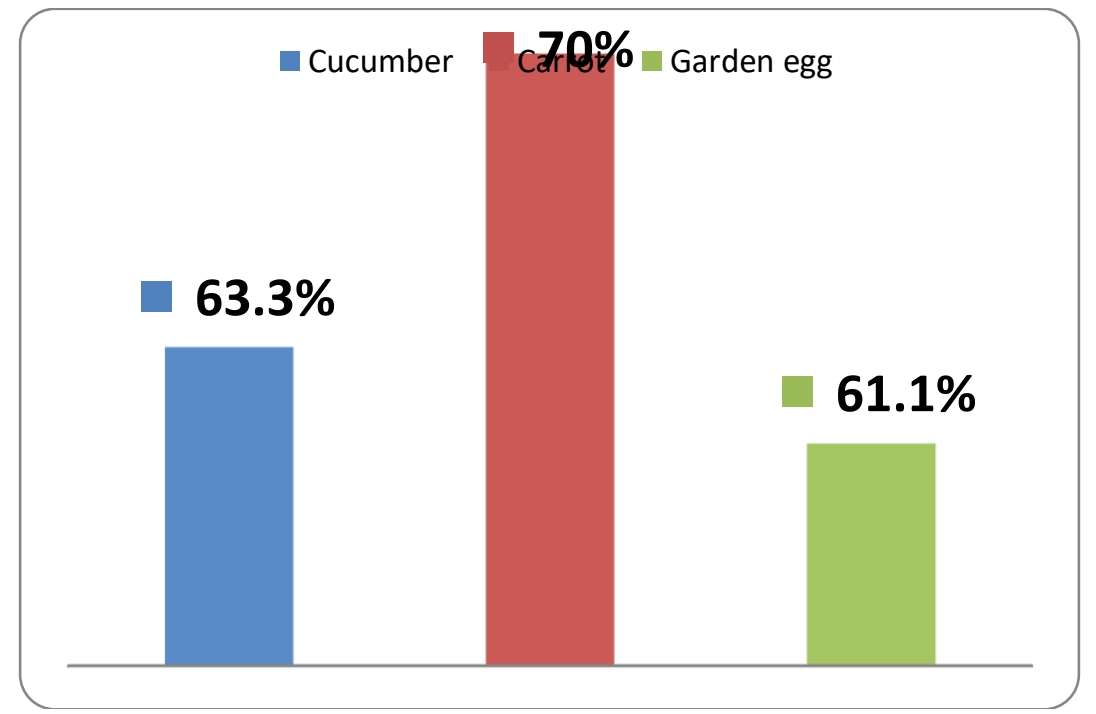

Figure 1: Percentage of vegetable contamination based on vegetable type

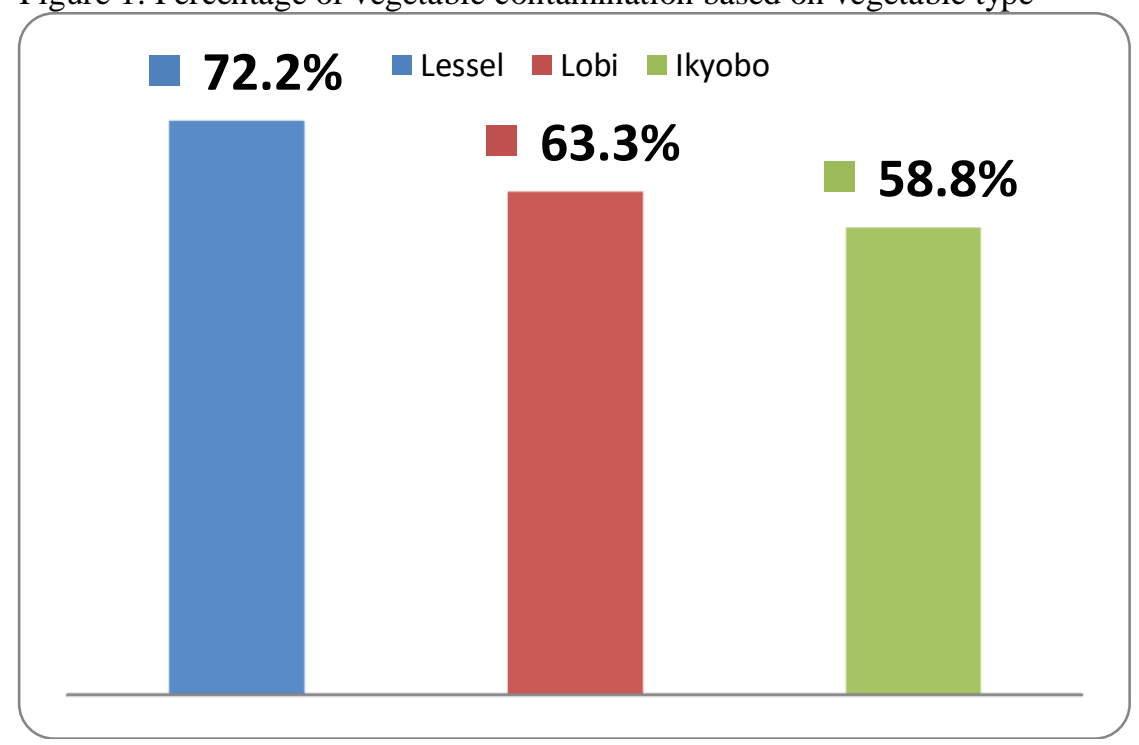

Figure 2: Percentage of vegetable contamination based on market type

Table 2 presents the frequency of egg density in cucumber. Entamoeba histolytica was the highest contaminant $(39 \%)$ occurring more in Lessel market than other locations. This was followed by Entamoeba histolytica (17\%) occurring Lobi and Ikyobo markets. Giadia lamblia (12\%) occurred equally in the three markets. Other isolated contaminants were Entamoeba nana (9\%), Entamoeba dispar (9\%), Hymenolepsis (5\%),
Giardia duodenalis (5\%) occurring in only Lobi market and Blastocystis hominis (4\%) present in only Ikyobo market. Thus, genus Entamoeba was the preponderant genera of contaminants in cucumber samples analysed in the study area. Consumers of cucumber are predisposed to diseases such as dystenteria, diarrhea and amoebiasis caused by Entamoeba infection. The affected locations are also at risk of disease outbreak. 
Assessment of Enteric Helminthes Ova on Ready to Eat Selected Vegetables (Garden Egg, Cucumber and Carrot) in Ushongo LGA of Benue State

Table 2: Frequency of helminthes egg density in Cucumber

\begin{tabular}{lccccc}
\hline Parasites & Lobi & Lessel & Ikyobo & $\begin{array}{c}\text { Total frequency of } \\
\text { contamination }\end{array}$ & $\%$ occurrence \\
Entamoeba histolytica & - & 14 & 8 & 22 & 39 \\
Entamoeba coli & 4 & - & 6 & 10 & 17 \\
Entamoeba nana & 3 & - & 2 & 5 & 9 \\
Blastocystis hominis & - & - & 2 & 2 & 4 \\
Giadia lamblia & 3 & 2 & 2 & 5 & 12 \\
Entamoeba dispar & 1 & 4 & - & 3 & 9 \\
Hymenolepsis & 1 & 2 & - & 3 & 5 \\
Giardia duodenalis & 3 & - & - & 57 & 100 \\
Total & 15 & 22 & 20 & & 5 \\
\hline
\end{tabular}

Table 3 gives the egg density isolated in carrot samples Entamoeba coli $(21 \%)$ in two locations and Entamoeba histolytica (21\%) occurring in all locations were the most occurring eggs isolated. This was followed by Chilomastix mesnili (16\%) occurring in all locations and Iodamoeba buestchili $(10 \%)$ found in only Ikyobo market. Others are: Trichuris trichiura (8\%), Ascaris lumbricoides (6\%), Entamoeba nana (6\%) and Ancyclostoma duodenale (5\%). Carrot samples contained more diverse species type as samples recorded all types of eggs isolated from protozoans and helminthes from different species. Worm infestation and other types of food borne diseases are likely to develop from carrot consumers. Table 4 presents the nature of eggs found in garden egg. Giardia lamblia was the most common contaminant $(33 \%)$ and it occurred in all locations. Also found were species of the genera Entamoeba and other species found in cucumber. Table 5 shows at a glance the frequency of occurrence of eggs among the 175 positive vegetable samples. A total of 14 egg types of different species were identified. Entamoeba histolytica (20\%), Entamoeba coli (19\%), Giardia lamblia (17\%) and Chilomastix mesnili (10\%) were the top four egg contaminants. Others species occurred in $<10 \%$.

Table 3: Frequency of egg density on Carrot

\begin{tabular}{|c|c|c|c|c|c|}
\hline \multirow[t]{2}{*}{ Parasites } & \multicolumn{3}{|c|}{ Markets } & \multirow{2}{*}{$\begin{array}{l}\text { Total frequency of } \\
\text { contamination }\end{array}$} & \multirow[t]{2}{*}{$\%$ of occurrence } \\
\hline & Lobi & Lessel & Ikyobo & & \\
\hline Giardia lamblia & 5 & - & - & 5 & 8 \\
\hline Chilomastix mesnili & 2 & 4 & 4 & 10 & 16 \\
\hline Entamoeba nana & 2 & 2 & - & 4 & 6 \\
\hline Ancyclostoma duodenale & 3 & - & - & 3 & 5 \\
\hline Entamoeba coli & 8 & - & 5 & 13 & 21 \\
\hline Entamoeba histolytica & 5 & 5 & 3 & 13 & 21 \\
\hline Trichuris trichiura & 1 & 4 & - & 5 & 8 \\
\hline Iodamoeba buestchili & - & - & 6 & 6 & 10 \\
\hline Ascaris lumbricoides & - & 4 & - & 4 & 6 \\
\hline Total & 26 & 19 & 18 & 63 & 100 \\
\hline
\end{tabular}

Table 4: Frequency of egg density on Garden egg

\begin{tabular}{lccccc}
\hline \multicolumn{3}{c}{ Markets } & \multicolumn{3}{c}{ Total frequency of } \\
contamination & $\begin{array}{c}\% \text { of } \\
\text { occurrence }\end{array}$ \\
Parasites & Lobi & Lessel & Ikyobo & 6 & 11 \\
Iodamoeba buestchili & 2 & 1 & 3 & 4 & 7 \\
Entamoeba dispar & 1 & - & 3 & 1 & 2 \\
Giardia lamblia & - & - & 1 & 2 & 33 \\
Ascaris lumbricoides & 6 & 4 & 8 & 11 & 4 \\
Entamoeba coli & - & 2 & - & 10 & 20 \\
Blastocystis hominis & - & 11 & - & 3 & 5 \\
Entamoeba nana & 4 & 6 & - & 55 & 10 \\
Total & 3 & - & - & & 5 \\
\hline
\end{tabular}


Assessment of Enteric Helminthes Ova on Ready to Eat Selected Vegetables (Garden Egg, Cucumber and Carrot) in Ushongo LGA of Benue State

Table 5: Total Parasitic occurrence of all parasites in vegetable samples

\begin{tabular}{lcc}
\hline Parasites & Total & (\%) of occurrence \\
\hline Entamoeba histolytica & 35 & 20 \\
Entamoeba coli & 34 & 19 \\
Iodamoeba belli & 6 & 3 \\
Chilomastix mesnili & 16 & 10 \\
Giardia lamblia & 30 & 17 \\
Entamoeba nana & 12 & 7 \\
Ancyclostoma duodenale & 3 & 2 \\
Trichuris trichiura & 5 & 3 \\
Ascaris lumbricoides & 6 & 3 \\
Iodamamoeba buestchilli & 4 & 2 \\
Entamoeba dispar & 6 & 3 \\
Blastocystis hominis & 12 & 7 \\
Giardia duodenalis & 3 & 2 \\
Hymenolepsis & 3 & 2 \\
Total & 175 & 100
\end{tabular}

The high prevalence $(37.1 \%)$ of Enteric helminthes ova recorded in Lessel could be attributed to exposure to predisposing factors such as, poor sanitary and hygienic conditions, unsafe sources of water and lack of awareness on the part of consumers and vendors This result is consistent with previous findings (Aguoru et al., 2015). The trend of parasitic infection reported through routine diagnosis is partly a factor of vegetables being sources of transmission (Al-Binal et al., 2006). The presence of intestinal parasites in vegetable samples is suggestive of faecal contamination as vegetables adequately harbor the infective forms of the parasites. Producers are also in the habit of using untreated animal dung and the use of raw affluent from human or animal wastes as manure leading to the transmission of zoonotic infection. The consumption of vegetables raw or undercooked is a possible way by which the transmission of these parasites is encouraged.

This is in agreement with previous work (JimenezGonzalez et al., 2007; Gibson, 1994) where high incidences of intestinal parasites were associated with environmental pollution and poor level of hygiene. In a similar study (Berger et al., 2000) conducted in other continent, Hookworm egg contamination was the highest contaminant isolated fruit samples whereas Entamoeba histolytica was the highest contaminant in the present report. The difference could be attributed to many prevailing conditions such as: different geographical location, climatic factors, environmental conditions, the general behavioral attitude to hygiene and the socioeconomic activities of producers, vendors and consumers (Jimenez-Gonzalez et al., 2007; Maya et al., 2012). It is obvious that vegetables consumed by people of Ushongo LGA are quite often contaminated with parasites, more especially by enteric helminthes ova. This might be responsible for the high cases of diseases such as cholera, typhoid, dysentery and other food borne diseases present in the study area. Amoah et al. (2007) and Aguoru et al. (2015) earlier suggested the use of common and improved sanitary washing method in many parts of Africa for the reduction of coliform bacteria and helminth eggs on fruits and vegetables sold in markets

\section{Conclusion}

Vegetables produced and sold in Ushongo LGA of Benue State are heavily contaminated with helminthes egg. This has implications in the health of the public. Farmers, vendors and consumers should be enlightened on the danger of consuming unwashed vegetables. Hygienic practices must be preached. Carrot was the most contaminated vegetable. From a total of 270 vegetable samples investigated, 175 were contaminated with helminthes egg belonging to 14 different species of helminthes, thus resulting in $64.8 \%$ level of vegetable contamination in Ushongo LGA. The three markets had equal chances of fruit contamination depending on the level of hygiene by the farmers, handlers and the source of contaminants.

\section{References}

1. Aguoru, C.U., Maaji, S and Olasan, J.O. (2015). Bacteria Contaminants on Surfaces of Some Edible Fruits Sold in Makurdi Metropolis, Benue State, Nigeria. International Journal of Current Microbiology and Applied Sciences, 4(6): 334-340.

2. Adamu, B. N., Adamu, Y. J and Dauda, M. (2012). Prevalence of helminth parasites found on vegetables sold in Maiduguri, Northeastern Nigeria. Food Control, 25 (1): 23 26

3. Al-Binali A.M., Bello C.S, El-shewy K and Abdullahi S.E 
(2006). The prevalence of parasites in commonly used leafy vegetables in South Western Saudi Arabia. Saudi Medical Journal, 27(5): 613-616

4. Amoah, P., Drechsel, P., Abaidoo, R.C and Klutse, A. (2007). Effective of common and improved sanitary washing method in selected cities of West Africa for the reduction of coliform bacteria and helminth eggs on vegetables. Tropical Medicine and International Health, 12: 23-26

5. Berger C.N, Sodha, S.V., Shew R.K. (2000). Fresh fruit and vegetables as vehicles for the transmission of human pathogens. Environmental Microbiology, 12(9): 2385-2397

6. Castro, G. A and Baron, S. (1996). Helminths: Structure, Classification, Growth, and Development. PMID 21413320.

7. CDC. (2014) Centers for Disease Control and Prevention, about parasites" CDC.

8. Cheesbrough, M. (2004). District Laboratory Practice in Tropical countries Part 1. Cambridge University Press, United Kingdom 178pp.

9. FAO (2010). Growing Green Cities. Food and Nutrition Security.www.fao.org/askfao.
10. Idahosa O.T (2011). Parasitic contamination of fresh vegetables sold in Jos markets. Global Journal of medical research (1): 20-25

11. Jimenez-Gonzalez D.E, Morguez-Rodriguez, K., Rodriguez, J.M, Gonzales, X., Oxford, J., Sanchez, R., Kawa-karasik, S. Flisseer, A., Maaravilla, P. (2007). Prevalence andrisk factors associated with intestinal parasites in a rural community of Central Mexico. J. Parasitol. Vector Biol. 1(2):009-012.

12. Jirillo, E., Mangrone, T., Miraglitta, G. (2014). Immunomodulation by Parasitic

13. Helminths and its Therapeutic Exploitation. Immune Response to Parasitic Infections, 12: 175-212.

14. Maya, C,. Torner-Morales, F.J, Lucario, E.S, Hernandez, E and Jimenez, B.(2012). Viability of six species of larval and non-larval helminth eggs for different conditions of temperature, $\mathrm{pH}$ and dryness. Water Res. 46: 4770-82

15. Syngletary, K.W., Jackson, S.J., Milner J.A (2005). Nonnutritive components in foodsas modifiers of the cancer process. 